\title{
ANALISIS PERBANDINGAN KEBUTUHAN ENERGI MENGGUNAKAN BOILER FEED PUMP DAN MOTOR INDUKSI PADA KONDISI START UP (STUDY KASUS: PLTU TANJUNG JATI B UNIT 3)
}

\author{
Muhammad Sagaf \\ Fakultas Sains dan Teknologi, Program Studi Teknik Elektro \\ Universitas Islam Nahdlatul Ulama Jepara \\ Email: sagaf_mnwr@yahoo.com \\ Safrizal \\ Fakultas Sains dan Teknologi, Program Studi Teknik Elektro \\ Universitas Islam Nahdlatul Ulama Jepara \\ Email: safrizal27@gmail.com
}

\begin{abstract}
ABSTRAK
Kebutuhan energi listrik yang semakin meningkat tidak hanya diikuti dengan peningkatan pasokan energi listrik saja, tetapi harus diikuti dengan pengelolaan energi yang baik dan efisien. Salah satu caranya yaitu dengan mengurangi penggunaan energi sendiri (auxiliary power) pada pembangkit listrik. PLTU Tanjung jati B Unit 3, yang mempunyai 2 Boiler Feed Pump (BFP) dengan penggerak Turbin uap (Turbine Boiler feed Pump atau TBFP) dan 1 buah BFP dengan pengerak Motor Induksi (Motor Boiler feed Pump atau MBFP). Penelitian ini dilakukan perbandingan peralatan tersebut yang bekerja dengan kebutuhan energi paling minimal. Proses pengambilan data dilakukan pada kondisi start up, cold 12 jam, warm 6 jam, hot 2 jam. Dari hasil penelitian menunjukan, untuk kondisi start up cold 12 jam MBFP mempunyai tingkat konsumsi energi 54,8 MWh, sedangkan TBFP hanya mengkonsumsi energy 21,6 Mwh, atau sebesar $60.58 \%$ dari jumlah energi yang digunakan oleh MBFP dan dapat menghemat biaya sebesar Rp 11.487.200,00 artinya TBFP mampu menghemat penggunaan energi 33,2 MWh atau setara 2.980 rumah berlangganan daya listrik PLN $1300 \mathrm{VA}$, konsumsi daya aktif rata-rata $11,14 \mathrm{kWh} /$ day (33.200 kWh/11,14 kWh = 2980unit rumah).
\end{abstract}

Kata kunci: PLTU TJB unit 3, TBFP, MBFP, start up cold, kWh, penghematan energi

\begin{abstract}
The increasing need for electricity is not only followed by an increase in the supply of electricity, must also be followed by good and efficient energy management. One way is to reduce the use of own energy (auxiliary power) in power plants. Tanjung Jati Power Plant B Unit 3, which has 2 Boiler Feed Pump (BFP) with a steam turbine (TBFP) and 1 BFP with an Induction Motor (MBFP) booster. This research is carried out comparing the equipment that works with the minimum energy requirements. Data retrieval process is carried out under conditions of start-up, cold 12 hours, warm 6 hours, and hot 2 hours. From the results of the study show, for the 12 hours cold start up condition MBFP has an energy consumption level of 54.8MWh, while TBFP only consumes 21.6 Mwh of energy, or as much as $60.58 \%$ of the amount of energy used by MBFP and can save costs by $R p$ 11,487.200.00 meaning that TBFP is able to save 33.2MWh of energy use or the equivalent of 2,980 homes subscribed to PLN 130VA electric power, the average active power consumption is $11.14 \mathrm{kWh} /$ day $(33,200 \mathrm{kWh} / 11,14 \mathrm{kWh}=2980$ housing units $)$.
\end{abstract}

Keywords: Power Plant B Unit 3, TBFP, MBFP, start up cold, $k W h$, energi saving 


\section{PENDAHULUAN}

Sistem tenaga listrik dewasa ini semakin rumit kompleks, permintaan kebutuhan tenaga listrik yang terus meningkat tiap tahun harus diikuti dengan peningkatan kualitas daya (power quality) serta biaya yang dapat diterima oleh pelanggan. Permasalahan krisis minyak dunia serta pemanasan global akibat pembakaran bahan bakar fosil jenis batu-bara oleh power plant untuk memproduksi tenaga listrik, oleh karena itu diperlukan pengelolaan energi listrik yang baik dan efisien. Salah satu cara yang dapat dilakukan adalah dengan meningkatkan efisiensi pembangkit listrik. Hal ini dapat dilakukan dengan mengurangi jumlah pemakaian listrik sendiri (auxiliary power) pada pembangkit listrik. Penelitian ini akan fokuskan pada analisa perbandingan kebutuhan dan efisiensi energi dari pompa pengisi air boiler / Boiler Feed Pump (BFP) yang digunakan pada pembangkit listrik tenaga uap Tanjung Jati B Unit 3 (PLTU TJB 3), dimana PLTU TJB 3 mempunyai 2 jenis Boiler Feed Pump yaitu Boiler Feed Pump penggerak Motor (MBFP) dan Boiler Feed Pump penggerak turbin uap (TBFP) saat kondisi start up. Setelah dilakukan perbandingan maka dapat ditentukan peralatan mana yang lebih efisien dan mempunyai konsumsi energi listrik yang lebih kecil.

\section{METODOLOGI PENELITIAN}

Penelitian oleh Aditasa Pratama, [1] melakukan studi untuk menentukan kapasitas motor listrik untuk pendingin dan penggerak pompa air high pressure pengisi boiler. Studi dilakukan pada saat beroperasi pada beban $100 \%$, dan didapatkan hasil daya output motor sebesar $576 \mathrm{~kW}$, daya input motor sebesar $770 \mathrm{~kW}$ dengan efisiensi motor $75 \%$. Sukamta [2], melakukan analisa unjuk kerja boiler feed pump turbine untuk kapasitas ketel uap 2000 ton/jam. Didapat hasil daya output (water horse power) sebesar $10027 \mathrm{~kW}$ dan input horse power (Brake horse power) sebesar $13521 \mathrm{~kW}$ dengan efisiensi sebesar 74,16\%. Jingkuan Li, [3][3] melakukan analisa ekonomis pada turbinedriven feed water pump. Pada beban yang semakin tinggi nilai efisiensi semakin meningkat dan nilai relative error antara calculation value dengan design value semakin menurun. Dengan kata lain didapat bahwa pada beban yang semakin tinggi permodelan menjadi semakin akurat.

Langkah kerja dalam penelitian ini oleh penulis dapat dilihat pada flowchart yang ditunjukkan oleh gambar 1 .

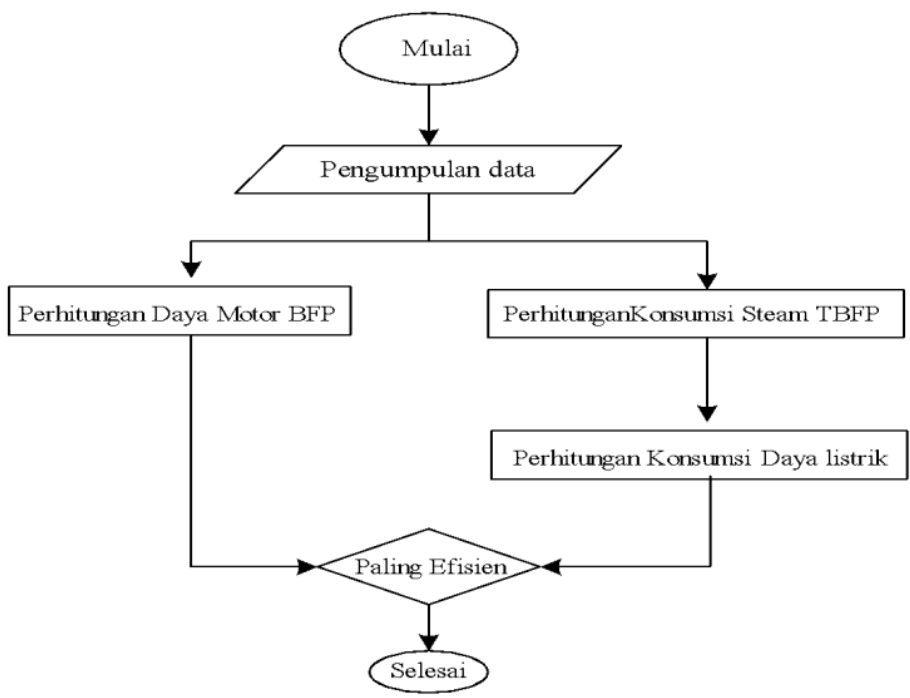

Gambar 1. Flowchart Penelitian 
Ada dua kategori metode dalam penelitian ini, yaitu metode pengumpulan data dan metode analisis data.

Metode pengumpulan data meliputi:

1. Data dokumen / data sekunder

2. Pengumpulan data langsung/data primer

\subsection{Boiler Feed Pump (BFP)}

Boiler Feed Pump merupakan salah satu aplikasi penggunaan pompa sentrifugal berukuran besar pada industri pembangkit listrik tenaga uap. Pompa ini berfungsi untuk mengontrol dan mengalirkan air pada jumlah tertentu yang berasal dari tangki Deaerator menuju boiler dengan spesifikasi tekanan tertentu (215 bar, pada PLTU TJB 3). Sebelum masuk ke boiler air tersebut biasanya mengalami pemanasan awal (pre-heating), sehingga air yang dipompa oleh BFP juga memiliki temperatur tertentu $\left(170{ }^{\circ} \mathrm{C}\right.$, pada PLTU TJB 3) yang cukup panas. Satu unit BFP pada PLTU terdiri atas dua pompa dan satu penggerak. Penggerak yang digunakan bisa berupa motor listrik atau juga turbin uap berukuran kecil. Turbin uap kecil tersebut mendapatkan aliran uap air yang diambil dari turbin uap utama pada stage tertentu (Intermediate Pressure Turbine/IPT). Satu unit PLTU TJB 3 pada penelitian ini menggunakan 2 BFP dengan penggerak Turbin Uap dan 1 Unit BFP dengan penggerak Motor induksi.

Satu unit BFP terdiri dari dua pompa yaitu satu booster pump dan satu main pump / pompa utama. Keduanya menggunakan penggerak tunggal (turbin uap atau motor), yang porosnya dicouple dengan atau tanpa sistem transmisi tergantung desainnya.

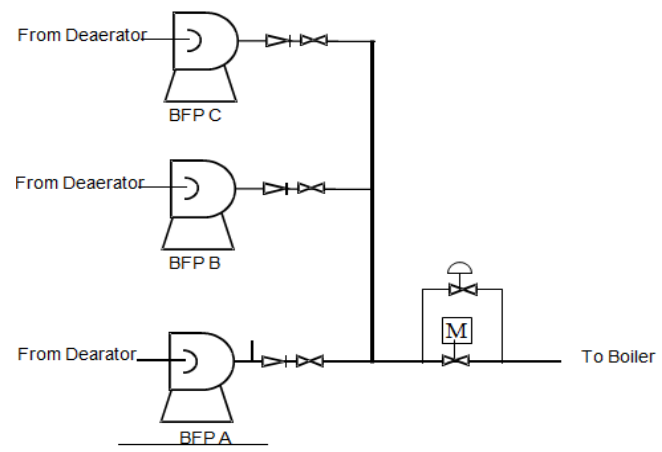

Gambar 2. Aliran Feed Water dari BFP

\subsubsection{Motor-BFP [4]}

Pada PLTU tanjung jati B Unit 3 terdapat sebuah BFP dengan penggerak 2 motor yang dikopling. Dimana spesifikasi sebagai berikut :

1. Manufaktur

2. Service name

3. Output

4. Voltage

5. Normal Current

6. Number of pole

7. Rated power factor

8. $\quad$ Speed synchronous/rated

9. IP Class

10. Locked rotor current

11. Starting time

12. Load characteristics:
: TOSHIBA

: Boiler Feed Water Pump

: $5600(\mathrm{~kW})$

$: 10000(\mathrm{~V})$

: 378 (A)

$: 4$

: 0.89

: 1500/1485 (rpm)

: IP55

$: 1706(\mathrm{~A})$

: $9.0(\mathrm{sec})$ 

a) Efficiency at $100 \%: 96.1 \%$
b) Efficiency at $75 \% \quad: 95.7 \%$
c) Efficiency at $50 \% \quad: 94.8 \%$
d) Efficiency at $25 \%: 91.3 \%$
e) Power factor at rated : 0.89
f) Power factor at starting : 0.15

Untuk Menghitung daya dari motor MBFP digunakan rumus [5]

Daya $(\mathrm{P})=V x I x \cos \varphi x \sqrt{3} V x I x \cos \varphi x \sqrt{3}$

\subsubsection{BFP Penggerak Steam Turbine (T BFP) [7]}

Terdapat 2 buah BFP dengan penggerak turbin uap dengan daya pompa yang sama sedangkan spesifikasi turbin nya adalah sebagai berikut

1. Type of Turbine : SCSF-10.5” (Single Cylinder Single Flow)

2. Rated Output (100\%ECR) : $14,086 \mathrm{~kW}$

3. Max Capacity : $14,749 \mathrm{~kW}$

4. Min Load Operation : $25 \%$ Load

5. Rated Speed : $5030 \mathrm{rpm}$

6. Direction of Rotation : CCW (Counter Clock Wise)

\subsection{Start up PLTU}

Pada Studi kasus yang dilaksanakan pada PLTU Tanjung Jati B Unit 3 didapatkan data waktu start up dengan 3 kondisi memulai start up.

\begin{tabular}{|c|c|}
\hline Mode Start & WAKTU \\
\hline Cold & $12 \mathrm{Jam}$ \\
\hline Warm & $6 \mathrm{Jam}$ \\
\hline Hot & 2 Jam \\
\hline
\end{tabular}

\subsection{Data Generator MW dan pemakaian steam di Turbin dan TBFP}

Tabel 2. Parameter Generator MW dan Konsumsi Uap 


\begin{tabular}{c|c|c|c|c|c}
\hline BEBAN & Coal Flow & MAIN STEAM & \multicolumn{3}{|c}{ Steam Flow } \\
\cline { 4 - 6 }$(\mathrm{MW})$ & $(\mathrm{t} / \mathrm{h})$ & FLOW $(\mathrm{t} / \mathrm{h})$ & TBFP A & TBFP B & TBFP Total \\
\hline 695 & 280.8 & 2231 & 44.82 & 45.63 & 90.45 \\
\hline 686 & 276.5 & 2186 & 44.84 & 54.67 & 90.51 \\
\hline 661 & 265.6 & 2086 & 44.92 & 45.79 & 90.71 \\
\hline 656 & 267.2 & 2068 & 43.29 & 44.05 & 87.34 \\
\hline 632 & 256.7 & 1975 & 41.48 & 41.97 & 83.45 \\
\hline 608 & 241.2 & 1905 & 38.95 & 39.29 & 78.24 \\
\hline 586 & 240.7 & 1814 & 36.81 & 36.92 & 73.73 \\
\hline 583 & 235 & 1793 & 35.43 & 35.99 & 71.42 \\
\hline 559 & 221.3 & 1673 & 33.38 & 33.87 & 67.25 \\
\hline 537 & 214.1 & 1637 & 32.04 & 32.52 & 64.56 \\
\hline 532 & 211.2 & 1622 & 31.58 & 31.87 & 63.45 \\
\hline 511 & 201.9 & 1533 & 29.5 & 29.85 & 59.35 \\
\hline 508 & 211.7 & 1610 & 29.19 & 29.44 & 58.63 \\
\hline 484 & 191.5 & 14.91 & 27.93 & 28.18 & 56.11 \\
\hline 455 & 186.7 & 1349 & 24.72 & 24.95 & 49.67 \\
\hline 383 & 159.9 & 1133 & 22.98 & 23.44 & 46.42 \\
\hline & & & & & \\
\hline & & & & \\
\hline 50 & & & & & \\
\hline
\end{tabular}

Pada Tabel 2. diatas menunjukkan energi listrik yang dihasil oleh PLTU TJB 3 dan konsumsi uap (steam flow) pada turbin utama dan pemakaian uap yang masuk ke 2 TBFP yaitu TBFP A dan TBFP B dimana jumlah konsumsi uap tersebut dijumlahkan menjadi TBFP steam flow.

\subsection{Harga Pembelian PLN}

Tabel 3. Harga Kwh Pembelian Oleh PLN

\begin{tabular}{r|l|c|c|c|c} 
No & \multicolumn{1}{|c|}{ PLTU Batubara } & $\begin{array}{c}\text { Harga } \\
\text { (Rp/kg) }\end{array}$ & $\begin{array}{c}\text { Nilai Kalor } \\
(\mathbf{k c a l} / \mathbf{k g})\end{array}$ & Rp/cal & $\begin{array}{c}\text { Merit } \\
\text { (Rp/kwh) }\end{array}$ \\
\hline 1 & Paiton 9 & 519 & 4,293 & 121 & 261 \\
\hline 2 & Tanjung Aw ar-Aw ar & 609 & 4,598 & 132 & 279 \\
\hline 3 & Rembang & 667 & 4,596 & 145 & 292 \\
\hline 4 & Suralaya 8 & 617 & 4,521 & 137 & 297 \\
\hline 5 & Indramayu & 628 & 4,604 & 136 & 297 \\
\hline 6 & Palabuan Ratu & 640 & 4,521 & 142 & 303 \\
\hline 7 & Paiton & 654 & 4,900 & 134 & 316 \\
\hline 8 & Pacitan & 705 & 4,733 & 149 & 334 \\
\hline 9 & Tanjung Jati 3\&4 & 1,007 & 5,647 & 178 & 346 \\
\hline 10 & Lontar & 619 & 4,539 & 136 & 350 \\
\hline 11 & Celukan Baw ang & 749 & 4,832 & 155 & 352 \\
\hline 12 & Tanjung Jati 1\&2 & 998 & 5,688 & 175 & 358 \\
\hline 13 & Cilacap 3 & 692 & 4,200 & 165 & 362 \\
\hline 14 & Banten & 749 & 4,200 & 178 & 369 \\
\hline 15 & Suralaya 400 & 783 & 4,848 & 162 & 384 \\
\hline 16 & PEC & 964 & 5,215 & 185 & 394 \\
\hline 17 & Labuan & 658 & 4,537 & 145 & 397 \\
\hline 18 & Japow & 911 & 5,000 & 182 & 397 \\
\hline 19 & Suralaya 600 & 783 & 4,758 & 165 & 398 \\
\hline 20 & PEC 3 & 943 & 5,000 & 189 & 401 \\
\hline 21 & CEP & 862 & 4,543 & 190 & 407 \\
\hline 22 & Cilacap 12 & 898 & 5,239 & 171 & 407 \\
\hline
\end{tabular}

Tabel 3. merupakan tabel harga pembelian listrik oleh PLN dari setiap pembangkit di Jawa Bali (JAMALI) per Agustus 2017 [7] 


\section{HASIL DAN PEMBAHASAN}

\subsection{Perhitungan Daya Motor Penggerak BFP}

Dari hasil perekaman data yang didapat dari DCS PLTU Tanjung Jati B Unit 3 didapatkan:
a. Tegangan Motor : $10 \mathrm{KV}$
b. Arus $\quad: 148 \mathrm{~A}$
c. $\operatorname{Cos} \varphi \varphi \quad$ : 0.89 (Data Sheet)

Sehingga daya motor dapat dihitung dari persamaan (1).

Daya $(\mathrm{P})=10 \mathrm{KV} x 148 \mathrm{Ax} 0.89 x \sqrt{3} 10 \mathrm{KV} x 148 \mathrm{Ax} 0.89 x \sqrt{3}$

Daya $(\mathrm{P})=2281.5 \mathrm{KW}$

Daya untuk 2 motor yang dikopling bersamaan sebagai pengerak BFP adalah

Daya $(\mathrm{P})=2281.5 \mathrm{KW}$ x 2 Motor

Daya $(\mathrm{P})=4563 \mathrm{KW}$ (saat start up)

Untuk menghitung energi yang dibutuhkan selama start up dapat digunakan tabel 1. Hasil perhitungan dari energi motor untuk setiap kondisi start up yaitu:

Tabel 4. Kebutuhan Energi Listrik MBFP

\begin{tabular}{ccc}
\hline $\begin{array}{c}\text { Kondisi } \\
\text { Start up }\end{array}$ & $\begin{array}{c}\text { Waktu } \\
\text { (Jam) }\end{array}$ & $\begin{array}{c}\text { Energi Motor } \\
\text { (MWh) }\end{array}$ \\
\hline Cold & 12 Jam & 54.8 \\
Warm & $6 \mathrm{Jam}$ & 27.4 \\
Hot & $2 \mathrm{Jam}$ & 9.1 \\
\hline
\end{tabular}

\subsection{Perhitungan Kebutuhan Uap Untuk setiap Energi Listrik}

Perhitungan jumlah aliran uap ( $\mathrm{t} / \mathrm{h}$ ) pada BFP yang dibutuhkan untuk setiap energi listrik yang dihasilkan menggunakan tabel 2. Dari data di tabel 2 dibentuk grafik sesuai gambar 3.

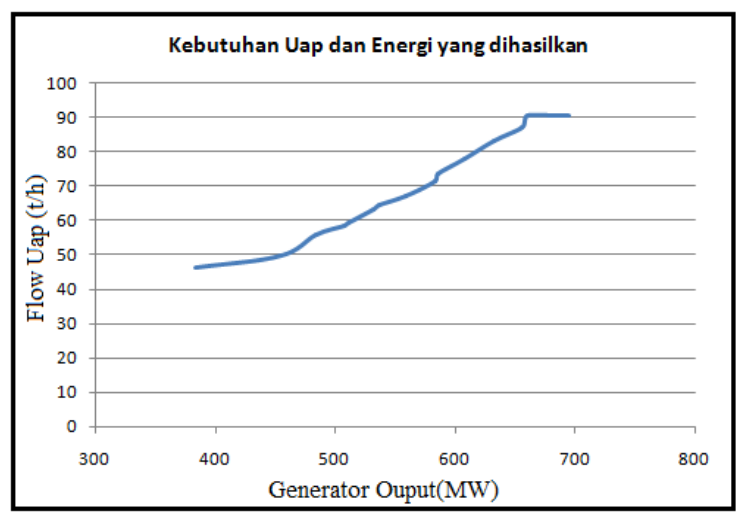

Gambar 3. Kebutuhan Uap Untuk Setiap Energi Listrik (MW)

Data pertama yang diambil dari tabel 2

Generator Output

TBFP A Steam Flow
: $695 \mathrm{MW}$

: $44.82 \mathrm{t} / \mathrm{h}$ 
Sehingga

Main Steam Flow

$: 2231 \mathrm{t} / \mathrm{h}$

\subsubsection{Kebutuhan Uap Main Steam}

Jumlah daya yang dihasilkan per ton uap main steam adalah $=695 \mathrm{MW} / 2231 \mathrm{t} / \mathrm{h}=0.31 \mathrm{MWh} /$ t Uap main steam.

\subsubsection{Kebutuhan Energi pada TBFP}

Jika pada saat start up TBFP yang dibutuhkan hanya 1 buah dengan asumsi bekerja saat daya penuh maka:

Daya $(\mathrm{MW})=0.31 \mathrm{MWh} / \mathrm{t} \times 44.82 \mathrm{t} / \mathrm{h}=13.89 \mathrm{MW}$ (saat full load)

Pada saat start up TBFP bekerja dibawah $25 \%$ beban generator. Berdasarkan data dari Digital Control system atau DCS, TBFP bekerja saat start up adalah 13\% dari kapasitasnya maka,

Daya $(\mathrm{MW})=13.89 \mathrm{MW} \times 13 \%$

Daya $(\mathrm{MW})=1.80 \mathrm{MW}($ Saat start up)

Kebutuhan energi listrik untuk semua kondisi start up sesuai tabel 5 adalah

Tabel 5 . Kebutuhan Energi Listrik TBFP

\begin{tabular}{ccc}
\hline Kondisi & Waktu & Energi TBFP \\
\hline Start up & (Jam) & (MWh) \\
\hline Cold & 12 & 21.6 \\
Warm & 6 & 10.8 \\
Hot & 2 & 3.6 \\
\hline
\end{tabular}

\subsection{Perbandingan Konsumsi Energi Listrik MBFP dan TBFP}

Dari hasil perhitungan yang telah dilakukan diatas maka dapat dilakukan perhitungan selisih pemakaian energi listrik antara MBFP dan TBFP. Adapun hasil perhitungannya dapat dilakukan sesuai dengan tabel 6.

Tabel 6. Perbandingan Energi MBFP dan TBFP

\begin{tabular}{|c|c|c|c|}
\hline Kondisi & Waktu & Energi & Energi \\
\hline Start Up & (Jam) & $\begin{array}{l}\text { MBFP } \\
\text { (MWh) }\end{array}$ & $\begin{array}{c}\text { TBFP } \\
\text { (MWh) }\end{array}$ \\
\hline Cold & $12 \mathrm{Jam}$ & 54.8 & 21.6 \\
\hline Warm & $6 \mathrm{Jam}$ & 27.4 & 10.8 \\
\hline Hot & $2 \mathrm{Jam}$ & 9.1 & 3.6 \\
\hline
\end{tabular}

\subsection{Pembahasan Penghematan Kondisi Start Up}

\subsubsection{Kondisi Start Up Cold}


Energi yang dapat di hemat adalah $=54.8-21.6=33.2 \mathrm{MWh}$ atau setara untuk penambahan pelanggan baru 2.980 rumah berlangganan daya listrik PLN 1300 VA, konsumsi daya aktif ratarata $11,14 \mathrm{kWh} /$ day $(33.200 \mathrm{kWh} / 11,14 \mathrm{kWh}=2980$ unit rumah $)$

Cost yang dapat dihemat = 33.2 MWh x Rp. 346 x $1000=$ Rp. $11.487 .200,00$

Persentase penghematan $=33.2 \mathrm{MWh} / 54.8 \mathrm{MWh}=60.58 \%$

Rp 346,00 biaya pokok produksi steam coal power plant.

\subsubsection{Kondisi Start Up Warm}

Energi yang dapat di hemat adalah $=27.4-10.8=16.6 \mathrm{MWh}$ atau setara untuk penambahan pelanggan baru 1490 rumah berlangganan daya listrik PLN $1300 \mathrm{VA}$, konsumsi daya aktif rata-rata $11,14 \mathrm{kWh} /$ day $(16.600 \mathrm{kWh} / 11,14 \mathrm{kWh}=1490$ unit rumah $)$

Cost yang dapat dihemat $=16.6 \mathrm{MWh} \times \mathrm{Rp} .346 \times 1000=\mathrm{Rp} .5 .743 .600,00$

Persentase penghematan $=16.6 \mathrm{MWh} / 27.4 \mathrm{MWh}=60.58 \%$

\subsubsection{Kondisi Start Up Hot}

Energi yang dapat di hemat adalah $=9.1-3.6=5.5 \mathrm{MWh}$ atau setara untuk penambahan pelanggan baru 5500 rumah berlangganan daya listrik PLN $1300 \mathrm{VA}$, konsumsi daya aktif rata-rata $11,14 \mathrm{kWh} /$ day $(5500 \mathrm{kWh} / 11,14 \mathrm{kWh}=493$ unit rumah)

Cost yang dapat dihemat $=5.5$ MWhx Rp. $346 \times 1000=\mathrm{Rp} 1.903 .000,00$

Persentase penghematan $=5.5 \mathrm{MWh} / 9.1 \mathrm{MWh}=60.44 \%$

Tabel 7. Penghematan Energi TBFP

\begin{tabular}{|c|c|c|c|c|}
\hline \multirow{2}{*}{$\begin{array}{c}\text { Kondisi } \\
\text { Start up }\end{array}$} & \multirow{2}{*}{$\begin{array}{c}\mathbf{u} \\
(\mathbf{J a m})\end{array}$} & $\begin{array}{c}\text { Energi } \\
(\mathbf{M W h})\end{array}$ & $\begin{array}{c}\text { Cost } \\
(\mathbf{R p})\end{array}$ & $\begin{array}{c}\text { Persen } \\
(\boldsymbol{\%})\end{array}$ \\
\hline Cold & 12 & 33.2 & 11487200 & 60.58 \\
\hline Warm & 6 & 16.6 & 5743500 & 60.58 \\
\hline Hot & 2 & 5.5 & 1903000 & 60.44 \\
\hline
\end{tabular}

\section{KESIMPULAN}

1. Penggunaan MBFP mempunyai konsumsi energi listrik yang besar dibandingkan TBFP.

2. Dengan penggunaan TBFP. Pemakaian energi listrik dapat dihemat sebesar $60.5 \%$ pada saat kondisi start up baik untuk cold start up, warm start up maupun hot start up.

3. Penghematan yang dilakukan ini hanya bisa dilakukan jika unit pembangkit pararel antara satu sama lain sehingga pembangkit yang sudah beroperasi dapat menyuplai kebutuhan uap untuk pembangkit yang memulai start up.

4. Dengan adanya pengematan ini dapat membantu mengurangi energi listrik untuk pemakaian sendiri (auxiliary power) sehingga dapat membantu meningkatkan pasokan energi listrik ke pelanggan.

\section{DAFTAR PUSTAKA}

[1] A. Pratama, "Studi Penentuan Kapasitas Motor Listrik Untuk Pendingin Dan Penggerak Pompa Air High Pressure Pengisi Boiler Untuk Melayani Kebutuhan Air Pada PLTGU Blok III (PLTG 3x112 MW \& PLTU 189 MW) Unit Pembangkitan Gresik,” Degree Electr. 
Engeenering RSE 62131 Pra 2010, Feb. 2010, Accessed: May 15, 2020. [Online]. Available: http://digilib.its.ac.id/ITS-Undergraduate-3100010038147/10424.

[2] S. Sukamta, S. Sudarja, and M. M. I. Wathon, "Analisis Unjuk Kerja Boiler Feed Pump Turbine Untuk Kapasitas Ketel Uap 2000 Ton/Jam Di PLTU Cirebon Jawa Barat,” Semesta Tek., vol. 18, no. 1, pp. 21-29, Jan. 2016.

[3] J. Li, H. Gao, and X. Hu, "An Economic Analysis of a Turbine-Driven Feed Water Pump," 2016.

[4] HARIANTO, “ANALISA EFISIENSI KALORI M-BFP (Motor Boiler Feed Pump) UNIT 1 DAN T-BFP (Turbine Boiler Feed Pump) UNIT 3 PLTU Tanjung Jati B JEPARA."

[5] M. Nahvi and J. Edminister, Schaum's Outline of Electric Circuts. Mcgraw-hill, 2002.

[6] "Theory_and_Problems_of_Electric_Circuits.pdf.".

[7] PT PLN (Persero) P2B, "Rencana Alokasi Energi September 2018," presented at the Rencana Alokasi Energi September 2018, solo, agustus 2018.

[8] "MBFP Motor Data Sheet.pdf.". 